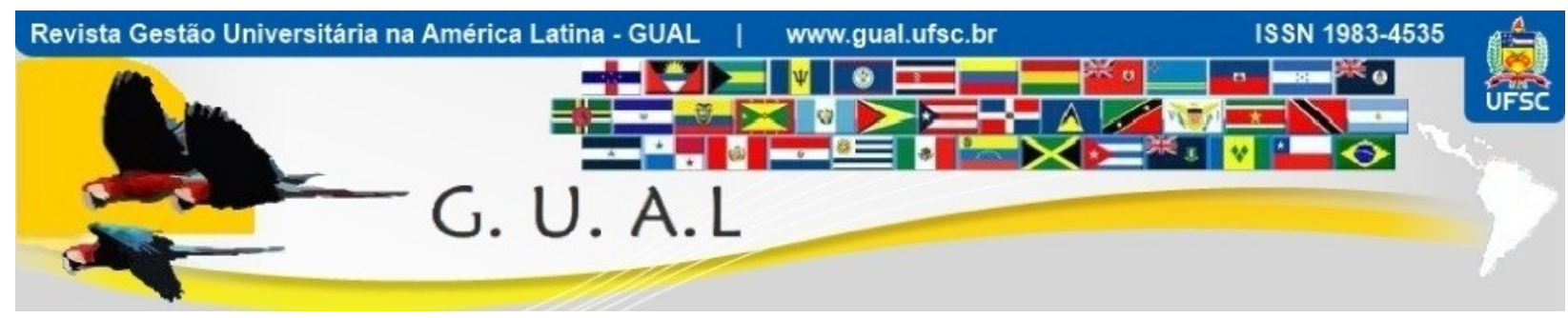

DOI: http://dx.doi.org/10.5007/1983-4535.2012v5n3p199

\title{
A IDENTIDADE INSTITUCIONAL DA UNIVERSIDADE BRASILEIRA SEGUNDO ATORES MACROSSOCIAIS RELEVANTES: CONVERGÊNCIAS E CONFLITOS
}

THE INSTITUTIONAL IDENTITY OF THE BRAZILIAN UNIVERSITY IN ACCORDANCE WITH MACROSOCIAL ACTORS: CONVERGENCES AND CONFLICTS

Angelo Brigato Ésther, Doutor Universidade Federal de Juiz de Fora - UFJF angelo.esther@ufjf.edu.br

Recebido em 18/setembro/2012

Aprovado em 13/novembro/2012

Sistema de Avaliação: Double Blind Review

Esta obra está sob uma Licença Creative Commons Atribuição-Uso. 


\title{
A IDENTIDADE INSTITUCIONAL DA UNIVERSIDADE BRASILEIRA SEGUNDO ATORES \\ MACROSSOCIAIS RELEVANTES: CONVERGÊNCIAS E CONFLITOS \\ DOI: http://dx.doi.org/10.5007/1983-4535.2012v5n3p199
}

\section{RESUMO}

A análise acerca da identidade institucional da universidade brasileira é uma tarefa árdua, na medida em que há discursos de diversos atores sociais com matizes político-ideológicas diversas e nem sempre convergentes, e que ganham "atualizações" ao longo do tempo histórico, de modo a não apenas evitar anacronismos, mas sobretudo encorpar a defesa de posições. Para tanto, muitos artifícios são utilizados, fazendo-se uso de estatísticas, comparações quantitativas e qualitativas, mas de modo nem sempre contextualizado. Neste artigo, é realizada uma análise acerca dos discursos oficiais, por assim dizer, dos que aqui denominamos "atores macrossociais relevantes", buscando identificar aspectos convergentes e divergentes, de modo a tentar clarificar como tais atores definem a instituição universitária brasileira, ou seja, como definem e descrevem a identidade institucional da universidade brasileira. Evidentemente, não se esgota o assunto nem as possibilidades, mas o objetivo é identificar a concepção central dos atores macrossociais em sua forma mais conceitual, ou seja, não se trata de identificar aspectos operacionais acerca das universidades. Ao contrário, trata-se de apontar e discutir as identidades defendidas e propostas, a partir da referência fundamental expressa na legislação brasileira, e que representa a posição do governo central.

Palavras-chave: Identidade institucional. Universidade brasileira. Educação superior.

\begin{abstract}
,
The analysis about the institutional identity of the brazilian university is an arduous task, to the extent that there are speeches of various social actors with various political-ideological perspectives not always convergent, which earn "updates" along the historical time, in order to not only avoid anachronisms, but above all folding in the defense of positions. For this porpose, many devices are used, making use of statistics, quantitative comparisons and quality, but in a way that is not always contextualized. In this article, we perform an analysis about the official speeches of what we call here "relevant macrosocial actors", seeking to identify convergent and divergent aspects, in trying to clarify how these actors define the institution of the university brazilian, i.e. as they define and describe the institutional identity of brazilian university. We do not end the matter nor the possibilities, but the goal is to identify the basic conception of macrosocial actors in its more conceptual aspect, i.e. it is not to identify operational procedures about universities. On the contrary, it is pointing out and discussing the identities defended and proposeds, from the fundamental reference expressed in brazilian legislation, that represents the position of central government.
\end{abstract}

Keywords: Institutional identity. Brazilian university. Superior education. 


\section{A IDENTIDADE INSTITUCIONAL DA UNIVERSIDADE BRASILEIRA SEGUNDO ATORES \\ MACROSSOCIAIS RELEVANTES: CONVERGÊNCIAS E CONFLITOS \\ DOI: http://dx.doi.org/10.5007/1983-4535.2012v5n3p199}

\section{INTRODUÇÃO}

A análise acerca da identidade institucional da universidade brasileira é uma tarefa árdua, na medida em que há discursos de diversos atores sociais com matizes políticoideológicas diversas e nem sempre convergentes, e que ganham "atualizações" ao longo do tempo histórico, de modo a não apenas evitar anacronismos, mas sobretudo encorpar a defesa de posições. Para tanto, muitos artifícios são utilizados, fazendo-se uso de estatísticas, comparações quantitativas e qualitativas, mas de modo nem sempre contextualizado.

Neste artigo, é realizada uma análise acerca dos discursos oficiais, por assim dizer, dos que aqui denominamos "atores macrossociais relevantes", buscando identificar aspectos convergentes e divergentes, de modo a tentar clarificar como tais atores definem a instituição universitária brasileira, ou seja, como definem e descrevem a identidade institucional da universidade brasileira. Evidentemente, não se esgota o assunto nem as possibilidades, mas o objetivo é identificar a concepção central dos atores macrossociais em sua forma mais conceitual, ou seja, não se trata de identificar aspectos operacionais acerca das universidades. Ao contrário, trata-se de apontar e discutir as identidades defendidas e propostas, a partir da referência fundamental expressa na legislação brasileira, e que representa a posição do governo central.

Como atores macrossociais relevantes foram consideradas as instituições representativas dos diversos segmentos universitários (professores, estudantes e servidores técnico-administrativos), dos dirigentes universitários, e do próprio governo federal, este representado pelo Ministério da Educação (MEC), sendo a Secretaria de Educação Superior $(\mathrm{SESu})$ entendida como a entidade fundamental que materializa a orientação governamental. O objetivo deste levantamento foi identificar a orientação institucional em nível macro, nacional, de modo a se desenhar uma posição político-ideológica mais ampla e representativa do conjunto dos atores sociais. O quadro 1, a seguir, aponta os atores macrossociais relevantes considerados.

As definições e concepções acerca da identidade institucional foram coletadas a partir da consulta e exame de documentos, leis e outros textos oficialmente publicados pelos atores macrossociais, inclusive em seus sites na internet, com também na mídia jornalística. Para a análise dos dados, buscou-se descobrir os "núcleos de sentido" que compõem os textos e documentos diversos, de acordo com o princípio básico da análise de conteúdo (BARDIN, 1995). 


\section{A IDENTIDADE INSTITUCIONAL DA UNIVERSIDADE BRASILEIRA SEGUNDO ATORES \\ MACROSSOCIAIS RELEVANTES: CONVERGÊNCIAS E CONFLITOS \\ DOI: http://dx.doi.org/10.5007/1983-4535.2012v5n3p199}

\begin{tabular}{c} 
MEC/SESu \\
(Ministério da Educação/Secretaria de Educação Superior) \\
ANDIFES \\
\hline ANDES - SN \\
(Associação Nacional dos Dirigentes das Instituic̃es Federais de Ensino Superior) \\
(Sindicato Nacional dos Docentes das Instituições de Ensino Superior ) \\
UNE \\
(União Nacional dos Estudantes) \\
FASUBRA \\
\hline (Federação dos Sindicatos de Trabalhadores das Universidades Brasileiras)
\end{tabular}

Quadro 1 Atores macrossociais relevantes considerados

Portanto, trata-se de uma análise interpretativa realizada a partir dos discursos oficiais ou formais elaborados pelos diversos atores macrossociais, com foco na universidade pública, notadamente na esfera federal.

\section{AS CONCEPÇÕES DOS ATORES MACROSSOCIAIS RELEVANTES}

\subsection{GOVERNO FEDERAL - MINISTÉRIO DA EDUCAÇÃO (MEC) / SECRETARIA DE EDUCAÇÃO SUPERIOR (SESU)}

O Ministério da Educação é responsável pela política nacional de educação. A educação superior, em particular, está sob responsabilidade da SESu, cujo papel é planejar, orientar, coordenar e supervisionar o processo de formulação e implementação da Política Nacional de Educação Superior, bem como a manutenção, supervisão e desenvolvimento das instituições públicas federais de ensino superior (IFEs) e a supervisão das instituições privadas de educação superior, conforme a Lei de Diretrizes e Bases da Educação Nacional $(\mathrm{LDB})^{1}$. Quanto ao nível de pós-graduação, as universidades funcionam, basicamente, sob os princípios e diretrizes da CAPES.

Em 1996, foi aprovada a atual Lei de Diretrizes e Bases da Educação Nacional LDBEN (Lei n. 9.394/1996), a qual define a finalidade da educação superior e das universidades. Em seu artigo 43, a lei estabelece que:

Art. 43. A educação superior tem por finalidade:

I - estimular a criação cultural e o desenvolvimento do espírito científico e do pensamento reflexivo;

II - formar diplomados nas diferentes áreas de conhecimento, aptos para a inserção em setores profissionais e para a participação no desenvolvimento da sociedade brasileira, e colaborar na sua formação contínua;

\footnotetext{
${ }^{1}$ Secretaria de Educação Superior. Disponível em: http://portal.mec.gov.br/index.php?option=com_content\&view=article\&id=287\&Itemid=354. Acesso em 25/02/2012.
} 


\section{A IDENTIDADE INSTITUCIONAL DA UNIVERSIDADE BRASILEIRA SEGUNDO ATORES \\ MACROSSOCIAIS RELEVANTES: CONVERGÊNCIAS E CONFLITOS \\ DOI: http://dx.doi.org/10.5007/1983-4535.2012v5n3p199}

III - incentivar o trabalho de pesquisa e investigação científica, visando o desenvolvimento da ciência e da tecnologia e da criação e difusão da cultura, e, desse modo, desenvolver o entendimento do homem e do meio em que vive;

IV - promover a divulgação de conhecimentos culturais, científicos e técnicos que constituem patrimônio da humanidade e comunicar o saber através do ensino, de publicações ou de outras formas de comunicação;

$\mathrm{V}$ - suscitar o desejo permanente de aperfeiçoamento cultural e profissional e possibilitar a correspondente concretização, integrando os conhecimentos que vão sendo adquiridos numa estrutura intelectual sistematizadora do conhecimento de cada geração;

VI - estimular o conhecimento dos problemas do mundo presente, em particular os nacionais e regionais, prestar serviços especializados à comunidade e estabelecer com esta uma relação de reciprocidade;

VII - promover a extensão, aberta à participação da população, visando à difusão das conquistas e benefícios resultantes da criação cultural e da pesquisa científica e tecnológica geradas na instituição.

As universidades compõem o Sistema Federal de Ensino Superior, o qual é regido pela LDBN e pelo decreto n. 2.306/1997, e coordenado pela Secretaria de Ensino Superior do Ministério da Educação (SESu/MEC). O sistema federal apresenta a seguinte organização (NEVES, 2002):

- Instituições universitárias

- Universidades

- Universidades especializadas

- Centros universitários

- Instituições não universitárias

- Institutos superiores de educação

- CEFETs (Centros Federais de Educação Tecnológica) e CETs (Centro de Educação Tecnológica)

- Faculdades isoladas

- Faculdades integradas

A figura 1 representa a articulação entre os níveis institucionais: o sistema federal como um todo, com todas as suas instituições e a regulação governamental à qual estão subordinadas, os órgãos de interlocução - a ANDIFES, no caso das universidades federais em particular, podendo-se incluir, para uma visão geral, os demais representantes dos discentes e dos servidores -, e as universidades individualmente consideradas.

Neste Sistema, a universidade é definida da seguinte forma (Decreto n. 9.394/1996):

Art. 52: As universidades são instituições pluridisciplinares de formação dos quadros profissionais de nível superior, de pesquisa, de extensão e de domínio e cultivo do saber humano, que se caracterizam por: 


\section{A IDENTIDADE INSTITUCIONAL DA UNIVERSIDADE BRASILEIRA SEGUNDO ATORES \\ MACROSSOCIAIS RELEVANTES: CONVERGÊNCIAS E CONFLITOS \\ DOI: http://dx.doi.org/10.5007/1983-4535.2012v5n3p199}

I - produção intelectual institucionalizada mediante o estudo sistemático dos temas e problemas mais relevantes, tanto do ponto de vista científico e cultural, quanto regional e nacional;

II - um terço do corpo docente, pelo menos, com titulação acadêmica de mestrado ou doutorado;

III - um terço do corpo docente em regime de tempo integral

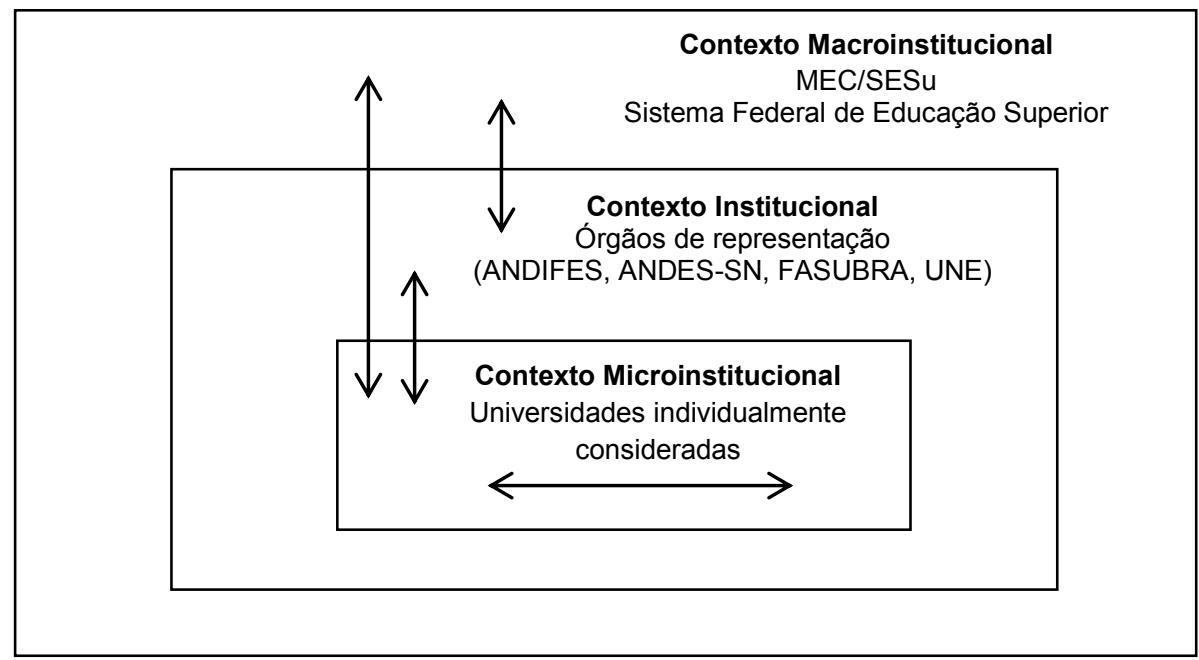

Fonte: Adaptado de Ésther (2007, p. 152)

Cabe à universidade, portanto, a preparar pessoal de nível superior para ocupar profissões, em todos os campos do saber humano, bem como realizar pesquisas e levar o conhecimento por meio de atividades de extensão, de forma perene, recorrente e articulada (interdisciplinar). Para tanto, precisa de pessoal dedicado (tempo integral), numa determinada proporção (um terço apenas do corpo docente) e com determinado nível de qualificação (mestrado ou doutorado). De acordo com o Decreto 5.773/06, as universidades públicas se caracterizam pela indissociabilidade das atividades de ensino, de pesquisa e de extensão.

A identidade institucional é colocada, fundamentalmente em termos da formação de quadros de recursos humanos de nível superior. Também se observa uma incongruência (ou contradição?) da própria definição de universidade, pois, na medida em que se define o princípio da indissociabilidade entre ensino, pesquisa e extensão, ao mesmo tempo se admite apenas um terço do corpo docente com pelo menos mestrado. Em outras palavras, dois terços podem não possuir titulação adequada aos fins a que se propõe, posto que o que garante aquela indissociabilidade reside no treinamento formal adquirido nos programas de mestrado e de doutorado, principalmente neste último. A universidade oficial, portanto, é definida dentro de um quadro de referência em que um princípio contradiz o outro. A universidade privada, contrariamente, não tem a obrigação de atender ao mesmo princípio norteador. Logo, 


\section{A IDENTIDADE INSTITUCIONAL DA UNIVERSIDADE BRASILEIRA SEGUNDO ATORES \\ MACROSSOCIAIS RELEVANTES: CONVERGÊNCIAS E CONFLITOS \\ DOI: http://dx.doi.org/10.5007/1983-4535.2012v5n3p199}

a definição de universidade é dúbia, pois o que vale para a esfera pública não vale para a esfera privada.

Ao se definir a universidade por meio daquilo que ela faz, o decreto define a identidade institucional da universidade brasileira. Ou seja, sua identidade institucional é finalística, na medida em que a define a partir daquilo que deve fazer, embora haja uma grande distância entre a universidade pública e privada no que tange ao princípio da indissociabilidade entre ensino, pesquisa e extensão.

Embora a definição oficial ressalte a busca do domínio e cultivo do saber humano, por meio de produção intelectual institucionalizada, é importante ressaltar que, na prática, os pesquisadores precisam possuir o título de doutor para obter financiamentos das agências de fomento ou das "fundações de apoio", pois as próprias instituições não possuem os recursos necessários em seus orçamentos. Neste aspecto em particular, entre 2000 e 2009, o país reduziu em cerca de $2 \%$ o investimento em educação superior, a despeito do crescimento de $67 \%$ em número de alunos nas universidades, segundo relatório da $\mathrm{OCDE}^{2}$.

De todo modo, o discurso governamental aponta assumir o papel estratégico da universidade - principalmente a pública - no desenvolvimento econômico e social, bem como consolidar as instituições públicas como referência para o conjunto das instituições de ensino superior do país. Ainda segundo o discurso oficial, a busca de competitividade nacional implica a ampliação do quadro profissional de nível superior, de modo a formar profissionais competentes para o setor produtivo. É de acordo com esta orientação que o governo lançou os controversos programas PROUNI e REUNI, em 2005 e 2007, respectivamente, de certo modo apoiados pelo sistema de avaliação criado em 2004, o SINAES.

O Sistema Nacional de Avaliação da Educação Superior (SINAES) foi criado em 2004, sendo formado por três componentes principais: a avaliação das instituições, dos cursos e do desempenho dos estudantes. O SINAES avalia todos os aspectos que giram em torno daqueles três eixos: o ensino, a pesquisa, a extensão, a responsabilidade social, o desempenho dos alunos, a gestão da instituição, o corpo docente, as instalações e vários outros aspectos.

Em janeiro de 2005, o governo lançou o Programa Universidade para Todos (PROUNI), que institui e refere-se "à concessão de bolsas de estudo integrais e bolsas de

2 Brasil ainda investe pouco em ensino superior, avalia OCDE. Disponível em http://noticias.terra.com.br/educacao/noticias/0,OI6145330-EI8266,00-

Brasil+ainda+investe+pouco+em+ensino+superior+avalia+OCDE.html. Publicado em 11/09/2012. Acesso em 17/09/2012. 


\section{A IDENTIDADE INSTITUCIONAL DA UNIVERSIDADE BRASILEIRA SEGUNDO ATORES \\ MACROSSOCIAIS RELEVANTES: CONVERGÊNCIAS E CONFLITOS \\ DOI: http://dx.doi.org/10.5007/1983-4535.2012v5n3p199}

estudo parciais de $50 \%$ ou de $25 \%$ para estudantes de cursos de graduação e seqüenciais de formação específica, em instituições privadas de ensino superior, com ou sem fins lucrativos". Segundo os críticos, consiste na "compra de vagas" nas instituições privadas pelo governo federal, para suprir a falta de vagas nas públicas.

Finalmente, baseado na meta de expansão da oferta de educação superior constante do Plano Nacional de Educação de 2001, destaca-se o lançamento do Programa de Apoio a Planos de Reestruturação e Expansão das Universidades Federais (REUNI), em 2007, cujo objetivo principal é dotar as universidades federais das condições necessárias para ampliação do acesso e permanência na educação superior ${ }^{3}$. O REUNI foi alvo - e ainda é - de muita controvérsia, originando diversos conflitos. Em várias universidades espalhadas pelo Brasil viram-se movimentos estudantis e docentes contrários ao programa, por entenderem que suas metas são elevadas demais, o que implicaria a queda de qualidade do ensino superior público. Em alguns casos houve até ocupação de reitorias por alunos. No entanto, o programa do governo reflete, pelo menos em parte, a proposta de diversos reitores de universidades federais ${ }^{4}$.

\subsection{ANDIFES}

A ANDIFES foi criada em 23 de maio de 1989, e é a representante oficial das instituições federais de ensino superior (IFES) na interlocução com o governo federal, com as associações de professores, de técnico-administrativos, de estudantes e com a sociedade em geral, de modo a defendê-la e protegê-la ${ }^{5}$. No entanto, somente com o governo do Presidente Lula a ANDIFES irá ser considerada quando das decisões acerca da política educacional para o nível superior, embora tal participação ainda não possa ser considerada adequada.

Para a ANDIFES, a universidade vem sendo definida como Órgão de Estado, patrimônio da sociedade e instituição estratégica para o desenvolvimento da nação, conforme os discursos dos seus últimos presidentes. $\mathrm{O}$ discurso atual aponta na direção da universidade como agente de desenvolvimento econômico, mediante formação de mão de obra qualificada para a chamada genericamente "sociedade do conhecimento", sem se discutir o que isto significa exatamente. $\mathrm{O}$ argumento se baseia nas premissas polêmicas da teoria do capital

\footnotetext{
${ }^{3}$ REUNI: Diretrizes gerais..., 2007.

${ }^{4}$ Ésther (2012).

${ }^{5}$ Ver: $h$ ttp: $/ /$ www.andifes.org.br/index.php?option=com content\&view=article\&id=93\&Itemid=64. Acesso em 28/07/2011. O estatuto pode ser encontrado neste endereço.
} 


\section{A IDENTIDADE INSTITUCIONAL DA UNIVERSIDADE BRASILEIRA SEGUNDO ATORES MACROSSOCIAIS RELEVANTES: CONVERGÊNCIAS E CONFLITOS DOI: http://dx.doi.org/10.5007/1983-4535.2012v5n3p199}

humano, em especial a de que o aumento na escolaridade proporciona aumento da renda individual, e que serviu de base para as políticas educacionais do governo militar. De todo modo, parece indicar uma "virada" no discurso do Estado-Nação e da perspectiva humanista, presente até o discurso de 2008 (Quadro 2), apesar de o discurso atual destacar a emancipação humana e preceitos éticos humanitários.

1. Segundo o Reitor João Martins, atual presidente da ANDIFES, são colocados os seguintes desafios às universidades, os quais expressam sua atuação desejada, portanto, seu papel:

- Adequar, academicamente, a universidade às novas demandas advindas da sociedade do conhecimento, que se fortalece cada vez mais neste início de século;

- Formar, estrategicamente, mão-de-obra qualificada para as necessidades sociais, econômicas e com padrões apropriados de sustentabilidade para este novo ciclo de crescimento e desenvolvimento que se expressa atualmente no país e no mundo;

- Produzir ciência, tecnologia e inovação para inserir o país, com soberania, na nova ordem mundial do conhecimento;

- Produzir e transmitir conhecimento que promova a igualdade, a inclusão e auxilie na formação de cidadãos emancipados e portadores de conceitos éticos e humanitários ${ }^{6}$.

2. As universidades federais são órgãos de Estado, e nós reitores, somos funcionários deste Estado, eleitos e com mandatos. Devemos, então, atuar de forma a preservar o papel da universidade na sociedade, como espaço de mediação, de crítica e de inovação, independente de governos. Sem receio de elogiar ou de criticar. Nenhuma instituição pode imaginar-se minimamente autônoma se não puder construir a defesa de seus atos, de sua política institucional e de sua integridade. Reivindicamos a autonomia universitária, do mesmo modo que consideramos crucial o controle externo de nossas ações.

Brasília, 13 de março de 2008 - Pronunciamento do presidente da ANDIFES, Arquimedes Diógenes Ciloni, reitor da Universidade Federal de Uberlândia, em reunião dos dirigentes das Instituições Federais de Ensino Superior com o Senhor presidente da República Luiz Inácio Lula da Silva.

3. A educação superior é um bem público, e nossas universidades representam um patrimônio da sociedade que levou décadas para ser construído. Esta afirmação ganha especial força e relevância nos dias atuais, frente ao ressurgimento de um discurso que qualifica a universidade pública brasileira como cara e ineficiente. Todos nós sabemos que, quando tratada como instituição estratégica para o desenvolvimento da Nação, participando assim do estabelecimento e concretização das políticas públicas do País, o investimento feito na universidade transforma-se em ganhos muito maiores para a sociedade. a universidade pública brasileira não é cara nem ineficiente. Ela é sim uma universidade de um país em desenvolvimento e, também, uma universidade que defende um modelo em que ensino, pesquisa e extensão são tratados como indissociáveis.

Discurso Reitor Oswaldo Duarte Janeiro de 2006. Reunião da ANDIFES com o Presidente Lula.

4. Universidades - e é esta sua identidade maior — nascem da confiança no conhecimento como forma de libertação de quaisquer obstáculos ao direito de homens e mulheres construírem uma vida sempre mais digna e sempre mais humana. Compromissada perenemente com valores humanistas, a Instituição Universitária mantém sempre uma dupla fidelidade - fiel à defesa da liberdade no cultivo do conhecimento e fiel à extensão dos benefícios decorrentes do conhecimento a parcelas cada vez mais amplas da população. O conhecimento, na diversidade de suas áreas, nas ciências e nas artes, nas tecnologias e na cultura, será sempre um instrumento contra a miséria que avilta, a ignorância que oprime e

\footnotetext{
${ }^{6}$ Retirado do documento "Discurso do Presidente da Andifes na reunião da Andifes com a Presidente Dilma Rousseff (13/12/2011). Disponível em http://www.andifes.org.br/index.php?option $=$ com content\&view $=$ article $\&$ id $=6043$ : andifes-se-reune-compresidente-da-republica-dilma-rousseff \&catid $=15 \&$ Itemid $=100$.
} 


\section{A IDENTIDADE INSTITUCIONAL DA UNIVERSIDADE BRASILEIRA SEGUNDO ATORES \\ MACROSSOCIAIS RELEVANTES: CONVERGÊNCIAS E CONFLITOS \\ DOI: http://dx.doi.org/10.5007/1983-4535.2012v5n3p199}

o medo que paralisa. Em uma sociedade como a brasileira, os ideais de excelência e de relevância devem orientar a ação de nossas IFES. A excelência acadêmica, em nossa compreensão, só pode ser entendida se vinculada a um projeto de construção de uma nação fraterna, solidária e justa, em que a riqueza e a qualidade de vida, geradas pelo conhecimento, sejam repartidas a todos. ... A autonomia constitui, a nosso juízo, não um fim, mas uma condição para que a excelência e a relevância se transformem em um só valor, essencial e estratégico. A pesquisa avançada, a ampliação e a democratização da abrangência da Universidade Pública Federal e a distribuição equilibrada de nossa base científica em todo o País são condições para o desenvolvimento regional e nacional e para a inserção competitiva do Brasil no cenário globalizado da sociedade do conhecimento... Que a educação se tornou uma área que afeta diretamente os interesses internacionais, prova-o o necessário combate contra os que querem, no âmbito da Organização Mundial do Comércio, tratar a educação como mercadoria. Urge formar, de modo especial em áreas estratégicas, um número crescente de profissionais capazes de alavancar e sustentar a produção de conhecimento no País. Profissionais com tal perfil, hoje alocados quase que exclusivamente nas Universidades, devem encontrar condições de atuação no setor produtivo... A Universidade autônoma é a Universidade altiva, academicamente qualificada e socialmente relevante.

Brasília, 27 de outubro de 2004. Reitora Ana Lúcia Almeida Gazzola. Presidente da ANDIFES. Reunião com o presidente Lula.

5. Para nós, a educação é um bem público e o conhecimento é um patrimônio social. ... A educação superior significa muito mais para um país do que a formação de bons profissionais. Um sistema de educação superior, solidamente enraizada nos problemas que desafiam o desenvolvimento social e econômico do nosso país, produz conhecimento e gera inovações tecnológicas... A educação superior pública, laica, republicana, gratuita e de qualidade ... gera compromisso e mobilidade social: ela inclui, ela forma cidadãos, ela produz riqueza moral, identidade e valores. Em um mundo marcado pela insegurança, pela desigualdade social, por ameaças ao meio ambiente e por tantos outros problemas, não seriam estas, entre todas, as nossas mais preciosas riquezas? ... A educação superior pública ... é muito mais do que uma rubrica do orçamento, é parte estratégica de um projeto social, de um projeto de nação - de uma nação que, com sua língua, sua cultura, suas artes, técnicas e ciências, sempre aberta para o universal, quer ser soberana e singular no concerto das nações ... a obra da educação superior pública brasileira não pertence a este ou aquele governo, mas atravessa gerações, por termos a convicção de que esta obra coletiva é patrimônio social...

Brasília, 5 de agosto de 2003. Pronunciamento da reitora Wrana Maria Panizzi, presidente da ANDIFES, em reunião dos dirigentes com o Sr. presidente da República Luiz Inácio Lula da Silva.

Quadro 2 Concepções da universidade segundo a ANDIFES, a partir do governo Lula

Destaca-se a formulação da então presidente da instituição, Reitora Ana Lúcia Gazzola, ainda em 2004, em reunião com o recém-empossado Presidente Lula:

Universidades - e é esta sua identidade maior - nascem da confiança no conhecimento como forma de libertação de quaisquer obstáculos ao direito de homens e mulheres construírem uma vida sempre mais digna e sempre mais humana. Compromissada perenemente com valores humanistas, a Instituição Universitária mantém sempre uma dupla fidelidade - fiel à defesa da liberdade no cultivo do conhecimento e fiel à extensão dos benefícios decorrentes do conhecimento a parcelas cada vez mais amplas da população ... A excelência acadêmica, em nossa compreensão, só pode ser entendida se vinculada a um projeto de construção de uma nação fraterna, solidária e justa, em que a riqueza e a qualidade de vida, geradas pelo conhecimento, sejam repartidas a todos (grifos nossos). 


\section{A IDENTIDADE INSTITUCIONAL DA UNIVERSIDADE BRASILEIRA SEGUNDO ATORES \\ MACROSSOCIAIS RELEVANTES: CONVERGÊNCIAS E CONFLITOS \\ DOI: http://dx.doi.org/10.5007/1983-4535.2012v5n3p199}

Em seu discurso, a formação de mão de obra qualificada não é estabelecida como parâmetro definidor da instituição universitária. Ao contrário, naquele momento, ainda se defendia a ideia da defesa de um projeto de nação, dentro do espírito da modernidade que se deseja alcançar historicamente. Ressaltam-se os valores humanistas e a melhoria do bem estar da sociedade por meio do conhecimento científico e sistemático. É dentro do espírito que se definia a excelência acadêmica, atrelada ao desenvolvimento social em primeiro lugar.

O mesmo teor pode ser observado no discurso da Presidente Wrana Panizzi, em 2003, quando recebida pelo Presidente Lula, ao afirmar que a "educação é um bem público", que "a educação superior significa muito mais para um país do que a formação de bons profissionais", e que a educação superior pública constitui "parte estratégica de um projeto social, de um projeto de nação", algo também observado no discurso de Osvaldo Duarte, em 2006 (ver quadro 2).

A definição do então presidente, Reitor Arquimedes Ciloni, coloca a universidade como um "órgão de Estado", e os reitores como "funcionários deste Estado". Define o papel da universidade como "como espaço de mediação, de crítica e de inovação, independente de governos. Sem receio de elogiar ou de criticar. Nenhuma instituição pode imaginar-se minimamente autônoma se não puder construir a defesa de seus atos, de sua política institucional e de sua integridade" (ver quadro 2).

Em 14 de setembro de 2011, a Associação Nacional dos Dirigentes das Instituições Federais de Ensino Superior - ANDIFES - realizou o "Seminário: Pós-Graduação, Inovação e a Expansão das Universidades Federais", na sede da instituição com a presença de diversas autoridades, dentre elas o Secretário da SESu/MEC, o presidente da CAPES, o presidente do CNPq, o Ministro da Ciência, Tecnologia e Inovação, além de diversos reitores, pró-reitores e mais de cem participantes.

Nesta reunião, dentre as diversas apresentações, ficou evidente a concepção da universidade pública como agente econômico, por meio de uma ação empreendedora, tal como preconizado por Burton Clark ${ }^{7}$. Pelo menos essa foi a posição de um dos reitores presentes, cuja apresentação foi disponibilizada no site da instituição ${ }^{8}$. Ou seja, está se

\footnotetext{
${ }^{7}$ Ver Clark (1998).

${ }^{8}$ Ver Andifes..., 2011. A referida apresentação encontra-se disponível no mesmo sítio, com o seguinte endereço: http://www.andifes.org.br/index.php?option=com docman\&task=doc download\&gid=660\&Itemid=27. Acesso em $01 / 12 / 2011$.
} 


\section{A IDENTIDADE INSTITUCIONAL DA UNIVERSIDADE BRASILEIRA SEGUNDO ATORES \\ MACROSSOCIAIS RELEVANTES: CONVERGÊNCIAS E CONFLITOS \\ DOI: http://dx.doi.org/10.5007/1983-4535.2012v5n3p199}

desenhando a identidade empreendedora da universidade, assumindo uma perspectiva que se aproxima visivelmente de uma perspectiva empresarial e privada.

\subsection{ANDES-SN}

Criado em 1981, durante a ditadura militar, como Associação Nacional dos Docentes do Ensino Superior, com a promulgação da Constituição Federal de 1988 passou a ser Sindicato Nacional dos Docentes das Instituições de Ensino Superior - ANDES-SN mantendo a sigla original. É o órgão que representa os docentes do ensino superior em nível nacional, apoiado pelos grupos de trabalho para a tomada de decisão e de posição.

Segundo consta do site do sindicato, suas "propostas para a universidade brasileira foram construídas a partir dos problemas históricos vivenciados pela maioria dos trabalhadores e enfrentados por inúmeros movimentos sociais que reivindicam emprego, transporte, moradia, terra, educação e saúde". Atualmente, conta com cerca de 70 mil sindicalizados de instituições federais, estaduais, municipais e particulares. ${ }^{9}$

Em seu site, o ANDES-SN afirma seus compromissos como sendo:

- "Lutar pela educação pública de qualidade, pela valorização do trabalho docente e pela autonomia das instituições públicas de ensino superior.

- Lutar pela universalização do acesso à educação superior pública e gratuita, com garantia de permanência.

- Lutar pelo espaço público para produção de conhecimento.

- Reforçar a unidade da classe trabalhadora no Brasil, internacionalmente e, em particular, na América Latina.

- Lutar contra toda forma de cerceamento à liberdade de organização sindical e de expressão.

- Lutar contra as reformas neoliberais que retiram direitos dos trabalhadores, especialmente a Reforma universitária privatizante.

- Combater todas as formas de mercantilização da educação"10.

Dentre seus sete compromissos, dois são dedicados à crítica da postura neoliberal/mercantilista da educação, além dos demais serem de natureza política, algo inerente a uma organização sindical. Formalmente, seus objetivos são:

- Manutenção e ampliação do ensino público gratuito e de qualidade socialmente referenciada.

- Autonomia e funcionamento democrático das universidades públicas e de direito privado, com base em colegiados e cargos de direção eletivos.

\footnotetext{
${ }^{9}$ ANDES - História. Disponível em http://antigo.andes.org.br/historia.htm. Acesso em 28/07/2011.

${ }^{10}$ ANDES - História. Disponível em http://antigo.andes.org.br/historia.htm. Acesso em 28/07/2011.
} 


\section{A IDENTIDADE INSTITUCIONAL DA UNIVERSIDADE BRASILEIRA SEGUNDO ATORES \\ MACROSSOCIAIS RELEVANTES: CONVERGÊNCIAS E CONFLITOS \\ DOI: http://dx.doi.org/10.5007/1983-4535.2012v5n3p199}

- Estabelecimento de um padrão unitário de qualidade para o ensino superior, estimulando a pesquisa e a criação intelectual nas universidades.

- Carreira única para os docentes das instituições de ensino superior.

- Indissociabilidade entre ensino, pesquisa e extensão.

- Dotação de recursos públicos orçamentários suficientes para o ensino e a pesquisa nas universidades públicas.

- Criação de condições de adequação da universidade à realidade brasileira.

- Garantia do direito à liberdade de pensamento nas contratações e nomeações para a universidade e no exercício das funções e atividades acadêmicas.

- Garantia do direito à liberdade de organização sindical em todas as instituições de ensino superior.

O ANDES $^{11}$ se posiciona contrariamente ao pressuposto neoliberal de "mercantilização" do conhecimento, algo observável no discurso da ANDIFES de 2004, em que a instituição se coloca contra tal perspectiva também. Porém, o movimento sindical continua contundente na defesa do caráter público da universidade, sendo esta sustentada pelo poder público e autônoma em relação a interesses específicos.

Em 2004, o sindicato marcou seu posicionamento em relação à recente política educacional do Presidente Lula, por meio de documento publicado em seu site, e realizado pelo Grupo de Trabalho de Política da Educação. O quadro 3, a seguir, apresenta um sumário de suas posições.

O ANDES-SN defende com todas as suas forças o direito de todos os que possuem um rosto humano à educação pública, gratuita e de alta qualidade em todos os níveis. Mais do que um intangível bem público, a educação é um dever do Estado. É inadmissível, para o ANDES-SN, que o mercado seja convocado pelo governo federal para garantir esse direito humano fundamental. $\mathrm{O}$ mercado nunca socializou direitos e jamais poderá fazê-lo.

$[\ldots]$

A defesa da tese de que o setor privado é "notoriamente mais eficiente" e que, portanto, a expansão deverá ter como eixo o fortalecimento das instituições particulares, por meio de parcerias entre o setor público e o privado (Parceria Público-Privada, PROUNI, Inovação Tecnológica, Documento II, Educação Profissional), apagando as distinções entre as esferas pública e privada é, para o ANDES-SN, o principal tema de discussão da agenda da educação superior.

$[\ldots]$

O ANDES-SN colocou em debate o seu Projeto para a Universidade Brasileira. Há significativos pontos de convergência entre essas proposições, mas também marcadas diferenças. Com democracia e, por conseguinte, com base no princípio de que esta requer direitos sociais e maior controle social da economia, as forças sociais que defendem a educação pública seguramente não irão se furtar a construir, em nome da nação brasileira, consensos que permitam a expansão do ensino superior público e de qualidade, o que requer políticas públicas que permitam a real democratização do acesso a esse nível de ensino em uma perspectiva de universalidade.

$[\ldots]$

O ANDES-SN envidará todos os seus esforços para não permitir que seja perdida essa oportunidade histórica em que a educação superior é repensada. O maior obstáculo para essa profunda transformação da educação superior reside no conteúdo e no método adotados pelo governo de Lula da Silva. Com efeito, o pressuposto fundamental de que a ampliação da oferta tem como eixo o setor privado, beneficiado por contratos de parcerias públicoprivadas, não levará à sonhada revitalização do setor público. Ao contrário, debilitará as instituições públicas que

${ }^{11}$ Embora a sigla se refira à nomenclatura antiga - Associação -, os textos assumem o artigo definido masculino para se referir a ANDES como sindicato, daí "O ANDES-SN", e não "A ANDES-SN".

Revista GUAL, Florianópolis, v. 5, n. 3, p. 199-221, dez. 2012

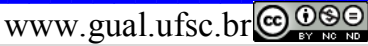




\section{A IDENTIDADE INSTITUCIONAL DA UNIVERSIDADE BRASILEIRA SEGUNDO ATORES MACROSSOCIAIS RELEVANTES: CONVERGÊNCIAS E CONFLITOS DOI: http://dx.doi.org/10.5007/1983-4535.2012v5n3p199}

se esvaecerão na mesma intensidade do apagamento das fronteiras entre o público e o privado, como quer o Executivo ao tratar toda a educação como um etéreo bem público ou um interesse social sem os verdadeiros significados dos adjetivos: público e privado.

Também o método compromete o necessário processo democrático. O exercício da democracia requer que as negociações sejam verdadeiras, o que pressupõe que todas as questões relativas ao futuro da educação superior sejam colocadas em discussão e não apenas o instrumento que lhes servirá de arremate final, como é o caso do Documento II "Reafirmando compromissos...". Não há democracia se não é possível discutir os conceitos básicos das ações governamentais.

$[\ldots]$

O Executivo Federal colocou em marcha a sua controversa política para a educação superior como um fato consumado, com base no mote: "o governo tem de governar." Não casualmente, reivindicou o uso generalizado de medidas provisórias.

$[\ldots]$

É necessária a criação de um espaço de discussão que inclua, além dos referidos instrumentos, a discussão das medidas heteronômicas criadas após 1988 que bloquearam o gozo efetivo da autonomia universitária. Igualmente, urge reverter, radicalmente, o laissez-faire que caracteriza o funcionamento e a expansão de instituições privadas. Somente atendendo a consistentes condições prévias estabelecidas pelo Estado - não passíveis de serem reduzidas a indicadores pontuais que acabam legitimando a existência de instituições que comprometem a credibilidade do sistema de ensino superior - podem as particulares atuar na educação superior. É importante destacar que o atendimento aos critérios públicos é condição prévia para que uma instituição privada possa fazer jus ao status de universidade e, por conseguinte, para a autonomia universitária.

O ANDES-SN propugna que o MEC tome para si a tese de que o eixo da expansão das vagas é o ensino público e gratuito e de que as polpudas verbas públicas que seriam repassadas para o setor privado, por meio das parcerias público-privadas, materializadas no PROUNI e no Documento II, sejam aplicadas nas instituições públicas, com o propósito de ampliar a oferta, um requisito necessário para democratizar o acesso em uma perspectiva universal $[\ldots]$

Quadro 3 Posicionamento sobre a chamada reforma da educação superior do governo de Lula da Silva Fonte: A contra-reforma da educação superior: uma análise do ANDES-SN das principais iniciativas do governo de Lula da Silva. Grupo de Trabalho de Política Educação - GTPE/ANDES-SN. Brasília, 2004, p.6-9.

Como se pode depreender do sumário acima, o ANDES-SN deixa clara sua posição contrária ao ordenamento político-institucional propugnado pelo governo federal, a despeito do então presidente da república ser oriundo do meio sindical. Para o sindicato dos docentes, o governo mantém as premissas neoliberais adotadas por FHC, implantadas desde Collor de Melo, relegando ao mercado o papel de agente econômico fundamental e atribuindo ao setor público o sinônimo de ineficiência. A crítica ao PROUNI é contundente, tendo o governo amenizado o problema com o lançamento e implantação do REUNI.

A análise de documentos mais recentes denota a manutenção do ANDES-SN em sua posição contrária ao ordenamento oficial. Como se pode ver a seguir, o sindicato defende a ampliação do debate acerca da universidade, de modo a torná-lo mais democrático e contextualizado (quadro 4).

No que se refere à universidade brasileira, reafirmamos que precisamos de uma radical transformação e não de uma reforma desta universidade. Precisamos de uma universidade que produza e socialize conhecimento novo, capaz de contribuir para a construção de uma sociedade justa e fraterna. Precisamos da educação pública, em 


\section{A IDENTIDADE INSTITUCIONAL DA UNIVERSIDADE BRASILEIRA SEGUNDO ATORES MACROSSOCIAIS RELEVANTES: CONVERGÊNCIAS E CONFLITOS DOI: http://dx.doi.org/10.5007/1983-4535.2012v5n3p199}

todos os níveis, que garanta acesso aos trabalhadores do campo e da cidade, que abra uma perspectiva aos milhões de jovens, nos estratos superiores e médios, que estão sendo levados para um consumismo exacerbado e um individualismo asfixiante e narcisista, cujo fim a mitologia grega já anteviu. Pior ainda é a situação da maioria da juventude que se vê cada vez mais distante da perspectiva de uma vida provida de sentido; que está sujeita ao extermínio e longe de poder acreditar, inclusive, na perspectiva de que a educação gere trabalho, no quadro de desemprego estrutural em que vivemos. Precisamos de ampliação de acesso com base numa expansão com qualidade e não a entrada dos jovens na universidade pela porta dos fundos. Precisamos da universidade que saiba responder aos desafios de uma sociedade que mantém dois terços de seus cidadãos afastados dos padrões mínimos de humanização alcançados historicamente. Na realidade brasileira, isso significa dizer que não basta pensarmos a universidade. Precisamos pensar a produção da ciência e da tecnologia e os órgãos de fomento à pesquisa, em especial a Capes e o CNPq: esses órgãos têm uma concepção instrumental sobre a produção do conhecimento e as formas possíveis de apoiar seu desenvolvimento. Ademais, mantêm o monopólio da definição das políticas e linhas de pesquisa, bloqueando a autonomia universitária. A transformação radical desses órgãos é uma condição importante na luta pela transformação da universidade a serviço dos interesses dos trabalhadores.

$[\ldots]$

Como produto das alterações na correlação de forças e do avanço da sociabilidade capitalista em todas as esferas da vida; combinada à ação organizada do governo Lula da Silva em calar a voz e frear a ação dos movimentos e entidades classistas, autônomos e combativos, temos um conjunto de medidas político-jurídicas que tentam deslegitimar o ANDES-SN. Com a promoção de oposição e rupturas na base da categoria, a concessão de cartas sindicais, incluindo a proibição de representação do ANDES-SN, o governo vem tentando mais do que nos calar e paralisar nossas ações, tenta nos destruir.

Quadro 4 - Posição político-ideológica do ANDES-SN em relação à universidade

Discurso da professora Marina Barbosa Pinto, na plenária de abertura do 55 CONAD. Disponível em http://antigo.andes.org.br/imprensa/ultimas/contatoview.asp?key=6687. Acesso em 17/09/2012.

Neste aspecto, o ANDES-SN aponta, desde o documento de 2004, a falta de um mecanismo democrático mais inclusivo, em que os atores sociais pudessem participar das discussões para formular a política pública de educação superior. O sindicato crítica o que eles chamaram de método do governo Lula (ver Quadro 3), ou seja, a forma como o governo federal conduziu a formulação das diretrizes e a implantação de programas.

Tal discussão deveria, em sua concepção, considerar não apenas a "questão da universidade", mas seu papel no contexto mais amplo da produção da ciência e da tecnologia, em que órgãos de fomento minam a autonomia universitária ao delimitar a agenda de pesquisa a ser realizada, uma vez que são as agências que financiam as pesquisas, e não a própria universidade, por meio de dotação específica para isto. Neste sentido, a autonomia e o financiamento são elementos fundamentais da estrutura e dinâmica universitárias.

\subsection{FASUBRA}

Fundada em 19 de dezembro de 1978, sob adenominação de "Federação das Associações de Servidores das Universidades Brasileiras", define-se como "entidade sindical democrática, sem caráter religioso ou político-partidário e independente em relação ao Estado, aos patrões e às administrações universitárias". Representa os trabalhadores das Instituições 


\section{A IDENTIDADE INSTITUCIONAL DA UNIVERSIDADE BRASILEIRA SEGUNDO ATORES \\ MACROSSOCIAIS RELEVANTES: CONVERGÊNCIAS E CONFLITOS \\ DOI: http://dx.doi.org/10.5007/1983-4535.2012v5n3p199}

de Ensino Superior (IES) e das Instituições vinculadas ao ensino superior, a ela associadas, em todo o território nacional. Defende a "perspectiva da construção de uma sociedade socialista, mais justa, igualitária e inclusiva e na defesa da educação pública, de qualidade, socialmente comprometida, concretizada cotidianamente, em conjunto com outras Entidades e movimentos sociais, bem como na construção da Universidade Cidadã para os Trabalhadores" $" 12$.

A FASUBRA elaborou uma proposta de Estatuto da Universidade Pública Autônoma, cuja definição central assim aparece formulada ${ }^{13}$ :

Artigo $4^{\circ}$ - A Universidade Pública Autônoma, através do ensino, da pesquisa e da

extensão, buscando contribuir para superar a alienação individual e coletiva e romper com o racismo e todas as formas de desigualdades sociais, rege-se a partir dos seguintes princípios:

I - garantia de Autonomia Institucional;

II - indissociabilidade entre ensino, pesquisa e extensão;

III - efetividade no cumprimento da função social de ensinar, pesquisar e praticar a extensão universitária necessária ao desenvolvimento sustentável do País;

IV - interação permanente com a sociedade e o mundo do trabalho;

$\mathrm{V}$ - integração e interação com os demais níveis e graus de ensino;

VI - garantia de condições para o acesso e permanência do aluno na instituição, assegurada a equidade de tratamento entre iguais e a justa e devida diferença entre os desiguais;

VII - liberdade de aprender, ensinar, criar, pesquisar e divulgar o pensamento, a

arte, a cultura, o saber em geral, a ciência e a tecnologia;

VIII - garantia da pluralidade e da livre expressão de orientações e opiniões;

IX - busca do desenvolvimento da formação cultural, técnico-científica do ser humano;

$X$ - capacidade para o exercício de uma profissão, estimulando o desenvolvimento do espírito científico e do pensamento analítico-reflexivo; XI - preparo para participar da produção, sistematização e superação do saber acumulado;

XII - pluralismo de idéias e de concepções pedagógicas;

XIII - adoção de um padrão unitário de qualidade;

XIV -gestão democrática e colegiada;

XV - eficiência, eficácia e efetividade na consecução dos objetivos institucionais;

XVI - racionalização no uso dos recursos da instituição;

XVII - valorização profissional dos trabalhadores em educação;

\footnotetext{
${ }^{12}$ Ver http://www.fasubra.org.br. Histórico. Acesso em 17/08/2012.

${ }^{13}$ Projeto Universidade cidadã para os trabalhadores. Revista da FASUBRA, n.2, julho de 2005. Disponível em http://www.sindifes.org.br/sindifes/admin/arquivos/Projeto\%20Universidade\%20Cidada\%20para\%200s\%20Tra balhadores.pdf. Acesso em 17/09/2012.
} 


\section{A IDENTIDADE INSTITUCIONAL DA UNIVERSIDADE BRASILEIRA SEGUNDO ATORES \\ MACROSSOCIAIS RELEVANTES: CONVERGÊNCIAS E CONFLITOS \\ DOI: http://dx.doi.org/10.5007/1983-4535.2012v5n3p199}

XVIII - gratuidade de todas as atividades acadêmicas: ensino de graduação, de pós-graduação (mestrado, doutorado, especialização e aperfeiçoamento) e de extensão.

Como se pode perceber, a declaração de princípios denota uma perspectiva menos burocrática do que aquela estabelecida pela legislação vigente, ao estabelecer um rol de princípios fundamentais que norteiam sua atuação, nos quais seus objetivos devem se pautar, tal como expresso em seu artigo $5^{\mathrm{o}^{14}}$ :

I - promover o ensino, a pesquisa e a extensão universitária, de forma indissociável, com padrões elevados de qualidade social e equidade;

II - promover o desenvolvimento científico, tecnológico, econômico, social, artístico e cultural, em todas as áreas do conhecimento;

III - atuar no sentido de superar os problemas regionais e nacionais;

IV - formar cidadãos capacitados para o exercício crítico da investigação e do magistério em todas as áreas do conhecimento e qualificá-los para as atividades profissionais;

$\mathrm{V}$ - estender à comunidade serviços indissociáveis das atividades de ensino e de pesquisa, levando em conta seus anseios e necessidades contextuais;

VI - desenvolver e difundir os valores éticos e de liberdade, igualdade e democracia;

VII - estimular a solidariedade humana na construção da sociedade, no respeito à vida e na estruturação do mundo do trabalho;

VIII - educar, para conservação e preservação da natureza;

IX - propiciar condições para transformação da realidade, visando a justiça social e o desenvolvimento auto-sustentável;

$\mathrm{X}$ - ampliar o acesso da população à educação superior, visando a sua universalização;

XI - desenvolver ações para o fim de todos os preconceitos raciais, de gênero e sociais e relativos às opções políticas, religiosas e de orientação sexual.

XII - preservar e resgatar a memória cultural do país.

Os princípios e objetivos não destacam a formação de quadros de recursos humanos como elemento central e definidor da universidade, tal como se observa na definição oficial vigente. Ao contrário, defende ideais que se podem chamar mais "humanistas", e de uma forma atualizada em relação aos princípios defendidos pelos intelectuais da "Escola Nova", tais como Anísio Teixeira e Fernando de Azevedo e, mais recentemente, Darcy Ribeiro e Florestan Fernandes.

Além disto, a proposta da FASUBRA inclui o princípio básico da autonomia e do financiamento público, tal como defendido pelo governo federal atual, pela ANDIFES e pelo ANDES-SN. No entanto, diferentemente do governo central e da ANDIFES, é contrária às fundações privadas que dão sustentação financeira às universidades.

\footnotetext{
${ }^{14}$ Idem.
} 


\section{A IDENTIDADE INSTITUCIONAL DA UNIVERSIDADE BRASILEIRA SEGUNDO ATORES \\ MACROSSOCIAIS RELEVANTES: CONVERGÊNCIAS E CONFLITOS \\ DOI: http://dx.doi.org/10.5007/1983-4535.2012v5n3p199}

\subsection{UNE}

A UNE foi criada em 11 de agosto de 1937, no Rio de Janeiro, e passou a constituir a entidade máxima dos estudantes. Desde então, realizou diversos congressos anuais e atuou de modo efetivo em lutas políticas diversas ao longo de sua história. Teve sua atuação proibida pela ditadura militar em 1964, participou da movimentação política de 1968, apoiou a campanha "Diretas já" para a eleição de Tancredo Neves para a presidência da república em 1985, participou da mobilização que levou ao impeachment do Presidente Fernando Collor de Mello em 1992, posicionou-se oficialmente contra a orientação de FHC e apoiou Lula para a presidência da república, dentre outras ações.

Atualmente, o site oficial da UNE não traz uma concepção acerca da universidade em destaque, mas aponta sua luta histórica em nome de uma "universidade democrática, de qualidade e sintonizada com um projeto de desenvolvimento para o país”. Destaca, ainda, como "bandeiras históricas do movimento estudantil" a "regulamentação do ensino privado, com foco nas mensalidades; ampliação das vagas públicas; garantia de mais verbas do orçamento federal da educação para o ensino superior público e a destinação de mais recursos para a assistência estudantil" ${ }^{\prime 15}$. O site ressalta a luta contra a mercantilização do ensino promovida pelo governo $\mathrm{FHC}$, bem como contra o sistema de avaliação implementado à época, o chamado "provão".

As informações disponíveis não permitem uma descrição e análise mais profunda acerca de seu posicionamento político-ideológico em relação às universidades, mas apontam no sentido da mobilização a favor do PROUNI e do REUNI, posição contrária àquela assumida pelo sindicalismo docente.

\section{CONSIDERAÇÕES SOBRE AS CONCEPÇÕES DOS ATORES MACROSSOCIAIS RELEVANTES}

A identidade da universidade é terreno contestado desde sua criação tardia em 1920. Desde então, parece haver um conflito político-ideológico que se perpetua e se reproduz atualmente, ainda que revestido (ou travestido?) de um discurso moderno e atualizado em que se antepõem ideais contraditórios ${ }^{16}$, na medida em que se defende ou uma universidade portadora e definidora de uma matriz identitária de nação, cuja ação deve ser desinteressada e

\footnotetext{
${ }^{15}$ UNE. Áreas de atuação. http://www.une.org.br. Acesso em 10/12/2011.

${ }^{16}$ Esther (2012)
} 


\section{A IDENTIDADE INSTITUCIONAL DA UNIVERSIDADE BRASILEIRA SEGUNDO ATORES \\ MACROSSOCIAIS RELEVANTES: CONVERGÊNCIAS E CONFLITOS \\ DOI: http://dx.doi.org/10.5007/1983-4535.2012v5n3p199}

com vistas ao desenvolvimento social, por meio de processos e pesquisas que não sofram a ação retaliadora do Estado ou de outros atores sociais, garantindo sua autonomia plena, ou uma universidade que deve ter como objetivo central o desenvolvimento, predominantemente econômico, cuja matriz teórico-ideológica é baseada na teoria do capital humano, e cujas ações devem visar o desenvolvimento científico-tecnológico e que o conhecimento gerado deve ser útil e aplicado para desenvolver o país e garantir os níveis de emprego da sociedade, gerando, portanto, seu bem estar.

Embora colocado em termos de uma dualidade e, neste caso, uma contradição, o conflito é mais complexo do que se possa perceber à primeira vista, pois ambas as concepções carregam consigo elementos que uma ou outra defendem em conjunto, e elementos que uma e outra atacam juntas, por assim dizer. Neste sentido, todos os atores sociais defendem o princípio fundamental da indissociabilidade entre ensino, pesquisa e extensão para a universidade pública, o qual não se aplica às universidades privadas, as quais, com isto, não se obrigam a contratar doutores, por exemplo. Deste modo, tem-se um "modelo duplo" de universidade, ou seja, a instituição universitária tem uma identidade "bipolar", se assim podemos chamar.

No entanto, ainda que se tenha como foco privilegiado de análise a universidade pública - e em especial a federal -, os atores sociais relevantes considerados são convergentes em uma série de elementos, mas distanciam-se em outros, o que gera certos conflitos e alguma dificuldade de aproximação entre eles, posto que parte de seus interesses são, também, em certa medida, conflitantes.

Por exemplo, os estudantes têm todo o interesse em que seja ampliada a oferta de vagas nas universidades, algo endossado por todos os atores sociais. No entanto, o crescimento recente, via REUNI, foi profundamente questionado em função da possível - e provável - queda da qualidade do ensino. Os próprios estudantes tomaram reitorias e os sindicatos foram fundamentalmente contrários à sua implantação, dada a crítica acima. Por outro lado, os dirigentes, representantes de suas instituições, acataram o programa governamental - cujas diretrizes tiveram o apoio da própria ANDIFES -, de modo a promover a expansão de suas universidades e aumentar seu capital político. Resta saber como os dirigentes obtiveram a aprovação dos respectivos conselhos universitários, dada a resistência docente e sindical. Em parte, compreende-se o apoio da ANDIFES em função de uma década de recursos escassos, sobretudo com o governo FHC. 


\section{A IDENTIDADE INSTITUCIONAL DA UNIVERSIDADE BRASILEIRA SEGUNDO ATORES \\ MACROSSOCIAIS RELEVANTES: CONVERGÊNCIAS E CONFLITOS \\ DOI: http://dx.doi.org/10.5007/1983-4535.2012v5n3p199}

Ao mesmo tempo, é importante levar em conta que o ideal de universidade empreendedora e formadora de capital humano está impregnado na universidade de modo geral. Isto implica afirmar que a universidade tem adotado a premissa de que, para ser eficiente, deve escolher áreas nas quais seja capaz de gerar maiores e melhores resultados, pois ela será avaliada por critérios quantitativos, os quais, por sua vez, são balizadores de aporte financeiro. Tal premissa explica, em grande medida, a prioridade e valor excessivo que se atribui à formação de mão de obra qualificada para o mercado de trabalho no interior das universidades. Tanto é assim que um dos indicadores fundamentais do "desempenho" institucional é a quantidade de estudantes formados ou graduados.

Neste ponto, reside outro aspecto polêmico e complicado: a questão da autonomia. Embora todos os atores sociais relevantes defendam a autonomia da universidade - tal como prevê a Constituição Federal de 1988, em seu artigo 207, que atribui à universidade "autonomia didático-científica, administrativa e de gestão financeira e patrimonial" -, na prática a situação é mais complicada. Por exemplo, a autonomia de gestão financeira é um fato, em termos. O orçamento tem de ser aprovado pelo Congresso Federal, mas a alocação dos recursos não permite flexibilidade suficiente para a tomada de decisões e sua implementação. Mas não há autonomia financeira. Ao mesmo tempo, há uma polêmica em torno da legalidade quanto à universidade pública captar e administrar recursos financeiros, especialmente por meio das chamadas fundações de apoio, dado o princípio fundamental e identitário da instituição pública e gratuita. Os sindicatos são contrários à manutenção das fundações. No entanto, os reitores fazem uso das mesmas, por vezes de forma indiscriminada e irresponsável, daí os problemas legais em torno da questão.

Além disto, a questão do financiamento implica a avaliação externa da universidade, o que tende a ser mal visto pela comunidade acadêmica, em função da possível perda de autonomia. Tal perda já pode ser observada no nível da pós-graduação, cujas agendas de pesquisa são avaliadas e julgadas exclusivamente por órgãos externos às instituições, tais como a CAPES e o CNPq, por exemplo.

Todo o debate está estruturado em torno de concepções fundamentais, cujo consenso está longe de ser obtido. Consenso este que deveria ocorrer em torno de, por exemplo, que modelo de universidade queremos ou precisamos. Ela deve ser pública? Ela deve ter como objetivo prioritário o desenvolvimento econômico, via conhecimento científico-tecnológico? Sua missão prioritária é formar mão de obra para o mercado de trabalho? O que é considerado 


\section{A IDENTIDADE INSTITUCIONAL DA UNIVERSIDADE BRASILEIRA SEGUNDO ATORES \\ MACROSSOCIAIS RELEVANTES: CONVERGÊNCIAS E CONFLITOS \\ DOI: http://dx.doi.org/10.5007/1983-4535.2012v5n3p199}

avanço científico? O que significa conhecimento como bem público? O ideal da modernidade pode ser ou foi abandonado? Qual o papel das humanidades neste contexto, vulgarmente chamado de globalização, em que a competitividade parece ser a finalidade básica? Como a universidade deve ser avaliada? Por quem? Por quais critérios?

Enfim, tais questões não são colocadas em debate, o que leva ao último ponto. Se o consenso não foi obtido, não é porque ele não é possível. Na verdade, ele nem foi tentado. Durante décadas, os governos tomaram para si a "responsabilidade", pela educação superior, mais ou menos de acordo com o ideal despótico do Marquês de Pombal, tão caro à elite brasileira, e segundo o qual só o Estado é capaz de realizar grandes reformas na universidade $^{17}$. O governo do Presidente Lula "chamou" a ANDIFES para o diálogo, o que é digno de nota. No entanto, resta saber: qual foi o tipo real de participação: mera aceitação ou colaboração efetiva? Mas, por que somente a ANDIFES? Por que não discutir com os sindicatos? Por que não dialogar com a entidade estudantil? Por que os atores sociais não são articulados entre si? Onde está a força histórica do movimento sindical e estudantil? Não se trata de uma "volta ao passado", uma "nostalgia ingênua" mas, ao contrário, trata-se de assumir o que constitui efetivamente uma sociedade democrática.

Assim, neste aspecto, tal como coloca Marilena Chauí, o ideal democrático no Brasil ainda está um tanto antiquado, pois a democracia não é apenas um regime político identificado à forma de governo. Ao contrário é uma forma geral de existência de uma sociedade, na qual o conflito é considerado legítimo e necessário e mediado institucionalmente para que possa ser expresso. Para a autora, "a democracia não é o regime do consenso, mas do trabalho dos e sobre os conflitos"18. Nesse sentido,

A sociedade brasileira é marcada pelo predomínio do espaço privado sobre o público e, tendo o centro na hierarquia familiar, é fortemente hierarquizada em todos os seus aspectos: nela, as relações sociais e intersubjetivas são sempre realizadas como relação entre um superior, que manda, e um inferior, que obedece. As diferenças e assimetrias são sempre transformadas em desigualdades que reforça a relação mando-obediência. O outro jamais é reconhecido como sujeito nem como sujeito de direitos, jamais é reconhecido como subjetividade nem como alteridade. As relações, entre os que se julgam iguais, são de "parentesco", isto é, cumplicidade; e, entre os que são vistos como desiguais, o relacionamento toma a forma do favor, da clientela, da tutela ou da cooptação, e, quando a desigualdade é muito marcada, toma a forma de opressão. Em suma: micropoderes capitalizam em toda a sociedade de sorte que o autoritarismo da e na família se espraia para

\footnotetext{
17 Torgal (2008).

${ }^{18}$ Chauí (2001, p.10).
} 


\section{A IDENTIDADE INSTITUCIONAL DA UNIVERSIDADE BRASILEIRA SEGUNDO ATORES \\ MACROSSOCIAIS RELEVANTES: CONVERGÊNCIAS E CONFLITOS \\ DOI: http://dx.doi.org/10.5007/1983-4535.2012v5n3p199}

a escola, as relações amorosas, o trabalho, os mass media, o comportamento social nas ruas, o tratamento dado aos cidadãos pela burocracia estatal, e vem exprimir-se, por exemplo, no desprezo do mercado pelos direitos do consumidor (coração da ideologia capitalista) e na naturalidade da violência policial $^{19}$.

É assim que o Estado tende a ofuscar o debate e a anular a reflexão, escamoteando as relações de poder, por meio de estratégias discursivas que colocam em evidência as necessidades da sociedade como se elas fossem totalmente claras e unanimemente aceitas como tal. Portanto, para aperfeiçoar a universidade, temos de avançar na prática democrática.

\section{AGRADECIMENTOS}

Este texto é resultado da conjugação de duas pesquisas realizadas. Assim, o autor agradece a CAPES pela bolsa de pós-doutoramento (Processo 6410-10-3) e a FAPEMIG pelo auxílio à pesquisa.

\section{REFERÊNCIAS}

ANDES - História. Disponível em http://antigo.andes.org.br/historia.htm. Acesso em 28/07/2011.

Brasil ainda investe pouco em ensino superior, avalia OCDE. Disponível em http://noticias.terra.com.br/educacao/noticias/0,,OI6145330-EI8266,00-

Brasil+ainda+investe+pouco+em+ensino+superior+avalia+OCDE.html. Publicado em 11/09/2012. Acesso em 17/09/2012.

CHAUÍ, Marilena. Escritos sobre a universidade. São Paulo: Unesp, 2001.

CLARK, Burton R. The entrepreneurial university: demand and response. Tertiary Education and Management, v.1 4, n.1, 1998.

CONAE 2010 - Conferência Nacional de Educação. Construindo o sistema nacional articulado de educação: o plano nacional de educação, diretrizes e estratégias de ação. Documento Final. Brasília: MEC, 2010. Disponível em http://conae.mec.gov.br/. Acesso em $10 / 11 / 2011$.

Discurso do Presidente da ANDIFES na reunião da ANDIFES com a Presidente Dilma Rousseff (13/12/2011). Disponível em http://www.ANDIFES.org.br/index.php?option=com_content\&view=article\&id=6043:ANDI FES-se-reune-com-presidente-da-republica-dilma-rousseff $\&$ catid=15\&Itemid=100.

\footnotetext{
${ }^{19}$ Chauí (2001, p. 13-14)
} 


\section{A IDENTIDADE INSTITUCIONAL DA UNIVERSIDADE BRASILEIRA SEGUNDO ATORES \\ MACROSSOCIAIS RELEVANTES: CONVERGÊNCIAS E CONFLITOS \\ DOI: http://dx.doi.org/10.5007/1983-4535.2012v5n3p199}

ÉSTHER, Angelo Brigato. A construção da identidade gerencial dos gestores da alta administração das universidades federais em Minas Gerais. Tese de Doutorado, CEPEAD/UFMG, Belo Horizonte, 2007.

ÉSTHER, Angelo Brigato. A universidade brasileira: tensões, contradições e perspectivas em sua trajetória. In NETO, Vítor (Coord.). República, universidade e academia. Coimbra: Almedina, 2012.

FASUBRA. Histórico. Disponível em http://www.fasubra.org.br. Acesso em 17/08/2012.

Projeto Universidade cidadã para os trabalhadores. Revista da FASUBRA, n.2, julho de 2005. Disponível em http://www.sindifes.org.br/sindifes/admin/arquivos/Projeto $\% 20$ Universidade $\% 20$ Cidada $\% 20$ para\%20os\%20Trabalhadores.pdf. Acesso em 17/09/2012.

REUNI - REESTRUTURAÇÃO E EXPANSÃO DAS UNIVERSIDADES FEDERAIS: DIRETRIZES GERAIS. Diretrizes Gerais. Brasília, 2007. Disponível em http://www.planalto.gov.br/ccivil_03/_Ato2007-2010/2007/Decreto/D6096.htm. Acesso em $01 / 10 / 2009$

Secretaria de Educação Superior. Disponível em:

http://portal.mec.gov.br/index.php?option $=$ com_content\&view $=$ article\&id=287\&Itemid=354 . Acesso em 25/02/2012.

TORGAL, Luis Reis. A universidade e as condições da imaginação. Cadernos do CEIS20, n.9. Coimbra, 2008.

UNE. Áreas de atuação. Disponível em http://www.une.org.br. Acesso em 10/12/2011. 